\title{
La lectura digital: perspectiva transhistórica y cognitiva
}

\section{Digital reading: trans-historical and cognitive perspective}

\author{
Elena Sánchez Muñoz \\ elena.sanchez.munoz@xunta.gal
}

\author{
Facultativo Superior de Bibliotecas en el Servizo do Sistema de Bibliotecas \\ de la Consellería de Cultura, Educación e Ordenación Universitaria de la \\ Xunta de Galicia
}

\section{Resumen}

Si algo ha caracterizado la lectura desde la invención de la escritura es su evolución vinculada bien a un cambio en los usos, bien a la aparición de nuevos soportes o a ambas circunstancias a la vez. El salto de la lectura "analógica" a la "digital" no es el primero que se produce a lo largo de este continuo, por lo que el análisis desde una perspectiva transhistórica nos permitirá comprender mejor el momento actual.

Paralelamente, conocer los procesos cognitivos que subyacen en el acto de leer nos proporcionará algunas de las claves para entender el funcionamiento de nuestro cerebro lector cuando lee "analógicamente" y "digitalmente".

\section{Palabras clave}

Lectura digital, Lectura analógica, Historia de la lectura, Libro electrónico, Libro impreso, Lectores

\begin{abstract}
If something has characterized reading from the invention of writing, it is its evolution bound to a change either in practice or to the emergence of new media or both circumstances at the same time. The leap forward from reading in print to reading onscreen is not the first one that occurs along this continuum, so the analysis from a trans-historical perspective will allow us to better understand the present.
\end{abstract}

In addition, knowing the cognitive processes that underlie the act of reading will provide some of the keys to comprehend how our reading brain works when it reads printed books and electronic books.

Keywords

Digital reading, Reading in print, History of reading, E-books, Print books, Readers 
Recibido:11/11/2016

Aceptado:2/05/2017

DOI: http://dx.doi.org/10.5557/IIMEI8-N14-067088

Descripción propuesta: SÁNCHEZ MUÑOZ, Elena, 2017. La lectura digital: perspectiva transhistórica y cognitiva. Métodos de Información, 8(14), pp. 67-88.

\section{Introducción}

La historia de la lectura está ineludiblemente unida a la evolución de nuestro cerebro. Éste está programado para realizar una buena parte de las tareas que desempeñamos cotidianamente pero no para leer. Aprender a leer implica reciclar regiones cerebrales destinadas a otras funciones. Este hito, alcanzado por los primeros hombres que fueron capaces de codificar y decodificar una sucesión de símbolos, se repite todos los días y tantas veces como un niño, en cualquier parte del mundo, aprende a leer.

El objeto de nuestro análisis es desentrañar los mecanismos que nos permiten leer y la forma en que lo hemos hecho a lo largo de la historia hasta llegar al momento actual. En qué medida la lectura digital cambia el modo en que leemos, escribimos y pensamos es uno de los grandes interrogantes que debemos plantearnos.

\section{La lectura y sus formas a lo largo de la historia}

Cualquier análisis sobre la evolución de la lectura ha de tener en cuenta dos factores: la forma de lo escrito y la identidad del público que lo interpreta. Tal y como afirma D.F. McKencie (1999) "Los nuevos lectores elaboran nuevos textos y sus nuevos significados están en función de sus nuevas formas".

Los "protolectores", o primeros lectores, surgieron en el Neolítico, en torno al VII milenio a.C. e interpretaban sistemas simbólicos denominados "protoescritura" que reflejaban elaboraciones de la mente mediante representaciones ideográficas. Ya en el 3200 a.C. la escritura sumeria presenta ideogramas en vías de evolución hacia una transcripción silábica. Este nuevo sistema "logosilábico" planteó una mayor exigencia a nuestro cerebro, incrementando las conexiones con las áreas visuales y la activación de más sistemas cognitivos (Wolf, 2008).

Los primeros alfabetos puros (los que emparejan un único símbolo a cada fonema) se remontan al II milenio a.C., en zonas como la antigua Nubia (actual Sudán) y Ugarit (actual Siria), donde se utilizaron como letras jeroglifos egipcios y signos cuneiformes respectivamente. El principio pro rebus, a partir 
del cual algunos ideogramas pasaron a representar el sonido inicial de la palabra representada a su vez por el ideograma, fue fundamental para el surgimiento de los sistemas alfabéticos.

El alfabeto, tal y como lo conocemos actualmente, nace en Grecia en el siglo VIII a.C. Basado en el fenicio (derivado, a su vez, del alfabeto sumerio), estaba formado por 24 caracteres que representaban todos los sonidos del lenguaje hablado. La gran aportación helénica a este sistema fonético consistió en la aplicación de signos para representar las vocales. El principio alfabético supuso una revolución de la escritura fonética que modificó los complejos sistemas existentes hasta entonces cuyo conocimiento estaba reservado a una élite muy reducida de nobles y escribas tras años de dedicación a su aprendizaje. La decodificación de la escritura alfabética, basada en la aplicación directa de las reglas de correspondencia que subyacen en la relación grafema/fonema, conlleva un nivel profundo de comprensión de la relación sistemática y representativa existente entre un grupo finito de letras y de sonidos.

Si bien el nacimiento de la escritura propició el desarrollo de un pensamiento novedoso al liberar a la mente de la necesidad de destinar una buena parte de sus procesos a la memorización vinculada a la cultura oral, fue el alfabeto el que contribuyó a que esas nuevas ideas estuvieran al alcance de más lectores y en una etapa más temprana del aprendizaje. El conjunto reducido de signos que lo constituyen hace que el lector necesite menos recursos de memoria y percepción facilitando así el aprendizaje de la lectura. Así mismo, el alfabeto resultó ser más eficaz porque podía ser leído y comprendido con mayor rapidez y fluidez (Wolf, 2008).

En torno al 750 a. C. se inicia la que podemos considerar como primera revolución lectora al producirse cierta "democratización" de la lectura. Así, en la Antigua Grecia, la lectura se entiende como un acto social que tiene por objeto dar sentido a la scriptio continua, un lógos escrito carente de intervalos. Esta incompletitud del texto hace necesaria la intervención de un lector que, con su voz, interpreta lo escrito leyéndolo a unos oyentes (que no lectores). A su vez, el lector cede su voz al escritor, sometiéndose así a lo escrito. En este sentido, se produce una relación simbiótica entre el homo scriptor y el homo loquens $^{1}$ de Poe (2010), es decir, entre una escritura dependiente de la oralidad y una oralidad supeditada a la escritura.

No obstante, se conservan testimonios que hacen referencia a la existencia de una lectura silenciosa ligada a la lectura extensiva. Para Knox (1968, citado en Svenbro, 2001), el manejo de grandes cantidades de texto por eruditos y 
poetas dramáticos en el siglo $\mathrm{V}$ a.C. posibilitó una lectura silenciosa, más rápida y minoritaria.

La expansión de la escritura y la "democratización" de la lectura no estuvieron exentos de crítica. En el S.V a.C., Sócrates alertó del peligro de la palabra escrita frente al discurso oral por considerar que la lectura daba acceso a un conocimiento sin orientación susceptible de ser interpretado erróneamente.

La época del Imperio Romano es un período de expansión de las prácticas de lectura gracias a la generalización de las bibliotecas públicas y privadas, el comercio del libro con la proliferación de las librerías y la progresiva implantación del codex.

La forma más habitual de leer sigue siendo en voz alta y el lector interpreta y marca las pausas de la scriptio continua. Eran habituales las recitaciones, esto es, el lanzamiento de obras literarias mediante su lectura en espacios públicos. Como consecuencia del aumento de grupos lectores entre la plebs, surge una literatura "de consumo". Tal y como afirma Cavallo (2001), los autores toman conciencia de la necesidad de responder a las expectativas del público tanto con obras que capten su atención (literatura erótica, opúsculos con recomendaciones para hacer un buen uso del ocio...) como facilitando la propia lectura (introducción, índices, etc.).

Existía también una lectura en espacios privados generalmente realizada por un esclavo lector. Así mismo, hay testimonios de lecturas por parte del propio autor ante un grupo de íntimos en las que éstos hacían comentarios críticos con el objetivo de mejorar el texto. Alberto Manguel (2012) recoge una carta de Plinio el Joven en la que éste se queja amargamente de que, en la lectura de una de sus obras, los asistentes "ban escuchado como si fuesen sordomudos. No ban despegado los labios..."

En todos los casos, la lectura no deja de ser un acto socializador y la lectura silenciosa, minoritaria.

A partir del siglo II d.C., y tras un período de convivencia, el códice empieza a sustituir al rollo. Nacido inicialmente como respuesta a la demanda de lectura, el codex se convierte en la alta Edad Media en un artilugio minoritario en una sociedad que, desde el siglo $\mathrm{V}$, deviene analfabeta. Con él, cambian las formas de lectura: de la visión panorámica y global del texto proporcionada por el rollo, se pasa a la fragmentación textual del códice en páginas, que facilita la lectura y la fijación de contenidos. La lectura libre y recreativa de la scriptio continua es sustituida por la lectura pautada y orientada de los codices distincti, provistos de signos de puntuación y diacríticos. Las palabras, ahora que ya no tienen una finalidad retórica, se separan introduciendo espacios para facilitar su lectura introspectiva. La lectura para el ocio y por el placer del texto recreado da paso a una lectura intensiva, reiterativa y silenciosa (a excepción 
de la liturgia) recluida en los monasterios. Así mismo, el códice cambia la propia "ergonomía" del lector, que puede leer con una sola mano al tiempo que escribe con la otra, en tanto que la "fisonomía" del códice propicia hacer anotaciones en los márgenes.

El nacimiento de la Escolástica a mediados del siglo XI constituyó un hito en la historia de la lectura e inició la evolución del homo scriptor al homo lector. El libro se convierte en un instrumento de trabajo intelectual y en una fuente para la obtención de conocimiento, dejando de ser así un mero depositario. La lectura sale de los monasterios y llega a la universidad. Se reflexiona sobre el acto de leer y el orden y organización de las lecturas. Para ello se introducen técnicas auxiliares como la titulación de los capítulos, sumarios e índices de contenido y alfabéticos con el fin de facilitar la consulta rápida. Por otro lado, la lectura total e intensiva de unos pocos libros da paso a una lectura fragmentada ante el gran incremento de manuscritos. La figura del librero adquiere un papel central dominando la producción. Conviven la lectura silenciosa y en voz alta, esta última comentada y explicada dentro de los programas de enseñanza.

Con la invención de la imprenta, el sistema de producción artesanal da paso a un sistema de producción en serie. Como consecuencia de la aceleración en la circulación de los textos y de la reducción de los costes por copia, hubo una amplia difusión de las ideas. No obstante, el impacto no fue inmediato, como atestigua el hecho de que los humanistas leían tanto manuscritos como impresos y que los tipos de estos últimos imitaban al inicio los caracteres de los amanuenses. El "ecosistema" del libro se expande y, además del lector, el autor y el librero, aparece el impresor y surge el lector "popular" (Chartier, 2001), entendido no sólo como mero oyente de la lectura en voz alta, sino como lector silencioso de extracción modesta.

Los tamaños y formatos se multiplican de modo que la presentación material determina la función, el tipo de lectura y el público al que se destina. Así, el libro en dieciseisavo permite al lector llevarlo consigo facilitando una lectura ininterrumpida e independiente de su ubicación, el panfleto reformista tiene por objetivo una lectura en voz alta ante un público en gran parte analfabeto, el pliego suelto se destina a la difusión de romances entre los lectores "populares" y el libro en folio a una lectura docta con atril.

El siglo XVIII ha sido bautizado como el de la segunda revolución lectora, caracterizada ésta por un notable incremento del público lector y una práctica lectora considerablemente más extensiva que la existente hasta entonces. No obstante, esta revolución debemos circunscribirla en sus inicios al estamento burgués. La aportación del movimiento ilustrado y el nacimiento de una conciencia de identidad individual están en la base de este interés en la lectura, convertida ahora en elemento emancipador y de ascenso social. 
Paulatinamente, el afán por leer se extiende entre las capas bajas de las ciudades que, al igual que la burguesía, tiene preferencia por las novelas y las publicaciones periódicas. Se observa una homogeneización en los gustos, la producción del libro está mediatizada por la demanda y se populariza el "libro de bolsillo" en formato octavo, dozavo y dieciseisavo. Las bibliotecas de préstamo comerciales (dotadas de fondos a menudo anticuados y orientadas a la literatura de consumo) inician su esplendor en la segunda mitad del siglo XVIII en contraposición con las sociedades literarias. De este modo, la lectura individualizada y anónima de las primeras fue sustituyendo progresivamente al debate en grupo y a la reflexión compartida en el seno de estas sociedades.

El siglo XIX es el de la alfabetización masiva de la sociedad occidental y la industrialización de la producción literaria. En el incremento sin precedentes del número de lectores hay tres elementos clave apuntados por Martyn Lyons (2001) y que resumimos en: feminización, infantilización y proletarización. Hubo, por un lado, una feminización del público lector que pasó a estar constituido, en la misma medida, por hombres y mujeres. Por otro, podemos hablar de una infantilización con la incorporación de los niños a la lectura a través de la escolarización. Por último, la proletarización tuvo su origen en la reducción de la jornada laboral, que contribuyó al incremento de lectores entre la clase obrera. Así mismo, se observa la vinculación de diferentes lecturas a determinados lectores en función del género y la edad: el hombre, ligado a la esfera de lo público, leía prensa; la novela imperante, cuya temática giraba en torno a los sentimientos y, por tanto, al ámbito de lo privado, tenía como principal destinatario el público femenino; por último, dirigida a los niños, surge con un marcado carácter didáctico y moralizante la literatura infantil.

Aunque la lectura silenciosa sigue siendo preponderante, la forma oral pervive entre la clase obrera en dos ámbitos: en público, con una lectura dirigida a los demás en los lugares de trabajo en los que noticias de prensa y panfletos políticos se leían en voz alta y, en privado, para sí mismos, por parte de aquellos obreros que convirtieron la lectura en un elemento esencial de superación personal. Estos autodidactas leían de manera intensiva y en vOz alta con el fin de absorber y memorizar los escasos libros de que disponían. Así mismo, entre la clase media, la lectura en voz alta pervivió en recitales públicos.

Los albores del siglo XX trajeron consigo el surgimiento de nuevos medios de comunicación y entretenimiento: el gramófono, el cine y la radio. Pero será posteriormente la televisión la que marque el nacimiento del homo videns (Sartori, 2002; Poe, 2010), caracterizado por privilegiar el sentido de la vista como medio de formación e información y que tiene como principal fuente de aprendizaje la televisión. En una época en la que el tiempo libre es limitado y las opciones de ocio casi ilimitadas, se producen más libros pero disminuye 
la población lectora. La lectura deja de ser el principal instrumento de culturización y de obtención de información, sustituida por lo audiovisual. Desde el punto de vista cultural, el hombre pasa de lector a espectador del mundo. Esta visión apocalíptica de la lectura no puede hacernos olvidar los nuevos lectores surgidos con las denominadas "tecnologías de la mente", expresión acuñada por Román Gubern (2010) para hacer referencia a aquellas tecnologías que tienen entre sus atributos más relevantes la capacidad de interactuar con los usuarios. De la pasividad ante la pantalla de televisión del homo videns, el nuevo homo somnians de Poe pasa a interactuar, escribir y leer, y lo hace a través de pantallas que actúan como interfaces visuales y táctiles. Lo digital revoluciona la lectura y remeda, a su vez, algunos hitos de la historia de ésta:

- La lectura, al igual que en la Antigua Grecia, deviene un acto social. A través de las redes sociales el lector puede valorar un libro, recomendarlo, publicar una anotación o emitir un comentario que es reproducido ad infinitum por otros lectores. Por otro lado, la lectura pierde su carácter privado: nuestros gustos, las horas a las que leemos, el tiempo que dedicamos o lo que subrayamos queda registrado en un servidor.

- La escritura fue cuestionada por Sócrates por constituir una forma no guiada de acceso al conocimiento sujeta a la interpretación del lector y fuente, por tanto, de pseudoconocimiento. La escritura online, desde la teoría literaria contemporánea, desafía la autoridad del texto y desdibuja los límites entre el autor y el lector. La premisa planteada en La muerte del autor por Roland Barthes, según la cual un texto escrito es un tejido de citas y referencias culturales que no pertenece a su autor sino al lector, tiene ahora mayor vigencia que nunca.

- Autores y lectores, situados hasta hace poco en los dos extremos de la cadena del libro, pueden prescindir de toda mediación hasta el punto de que empresas como Amazon, Apple o Barnes \& Noble ofrecen a los creadores servicios de autopublicación. Así como en la época romana los propios autores leían sus obras al público con el objeto de recibir críticas que les ayudasen a mejorar sus textos, los creadores actuales toman conciencia de las expectativas de los lectores y están atentos a sus comentarios a través de las redes sociales. Autor y lector interactúan directamente en este nuevo espacio.

- El paso del rollo al codex supuso una fragmentación textual por medio de la paginación que limitaba la visión panorámica que proporcionaba el rollo. Los dispositivos de lectura actuales permiten al lector repaginar los libros configurando el tamaño de la letra, los márgenes, etc. Es el propio lector el que cambia la fisonomía del libro a su gusto.

- Al igual que en la Edad Media, cambia la "ergonomía" del lector. Éste lee sentado ante la pantalla de un ordenador, caminando mientras lee 
un texto en un teléfono inteligente, o escuchando un audiolibro a la vez que practica una actividad física.

- Tal y como sucedió en la época escolástica, el libro electrónico facilita el trabajo intelectual: permite la búsqueda y recuperación de información dentro del propio texto, se establecen enlaces entre los índices de contenidos y los capítulos o entre las notas a pie de página, se incorporan diccionarios, enlaces externos que amplían los contenidos del libro, etc.

- El alfabeto y la imprenta contribuyeron a la rápida circulación de las ideas. Esta última también aportó un abaratamiento de los costes y la aparición de nuevos formatos. Del mismo modo, lo digital ha incrementado la velocidad a la que se difunden los textos, que llegan a millones de usuarios de forma casi inmediata: mensajes, noticias de prensa o el lanzamiento de un libro se hacen virales en cuestión de minutos. Los costes también se reducen, ya no tanto por la producción en serie como por la desintermediación que se produce en la cadena del libro (al contrario de lo que sucedió con la invención de la imprenta, el ecosistema del libro se reduce). Los dispositivos se multiplican y, en algunos casos, determinan la función: la lectura recreativa encuentra en las tabletas y, especialmente, en el lector de libro electrónico el soporte más adecuado; el trabajo de los textos con una finalidad académica se vincula al ordenador; se comercializan libros electrónicos de extensión reducida (de 5000 a 30000 palabras), conocidos como e-singles o short stories que contienen microrrelatos, libros por entregas, resúmenes e incluso relatos "a medida" según los gustos del lector para su lectura rápida en teléfonos inteligentes (Nook Snaps de Barnes \& Noble, Kindle Serials y StoryFront de Amazon, etc. ofrecen estos formatos). El lector puede proseguir la lectura de un dispositivo a otro y la movilidad es una de las características más determinantes de nuestro tiempo: circulan los textos y las ideas en ellos contenidas, como también circulan los lectores con las tecnologías móviles que acceden a los contenidos desde cualquier dispositivo y ubicación.

- La historia de la lectura es la de su progresiva democratización: desde la Antigua Grecia, a la alfabetización masiva en el siglo XIX, pasando por la revolución lectora del siglo XVIII.

El estadio en que nos hallamos actualmente constituye el embrión de una tercera revolución lectora, caracterizada por la diversificación de las formas de lectura y por el incremento del público lector que puede escoger entre una amplia oferta accesible, incluso, sin coste alguno: libros gratuitos (obras huérfanas o de autores que ceden sus derechos), artículos académicos publicados en acceso abierto, noticias de prensa de diarios digitales, contenidos web, etc. Por otro lado, la lectura llega a los países pobres o en vías de desarrollo gracias a las tecnologías móviles. Según el informe La lectura en la era móvil publicado por la 
Organización de las Naciones Unidas (West y Chew, 2015), allá donde los libros en papel no llegan, lo hacen los libros electrónicos a través de la tecnología móvil. Estos lectores leen más acumulativamente cuando empiezan a hacerlo en un dispositivo móvil y muchos neo y semianalfabetos utilizan sus teléfonos para buscar textos que se adecúen a su capacidad lectora.

- Se expanden los límites del texto: leemos, vemos, oímos, nos conectamos e, incluso, nos sumergimos en entornos aumentados. Los formatos, géneros $y$ temas se multiplican en la denominada "multiliteracidad".

Siguiendo la clasificación que hacen Gómez Díaz et al. (2016) de la bibliodiversidad tecnológica en función del elemento predominante, encontramos:

1. Materiales textuales sin interactividad

2. Materiales gráficos: cómics, novelas gráficas y revistas

3. Contenidos enriquecidos: incluyen información textual combinada con audio, imagen en movimiento, hipertexto, juegos y, en ocasiones, herramientas de participación en las redes sociales

4. Audiolibros y videolibros

5. Contenidos transmedia y crossmedia: la narración se expande a través de relatos que se desarrollan en múltiples medios. En los transmedia cada uno constituye una unidad por sí mismo y guarda su independencia, en tanto que en los crossmedia es necesario acceder a todas las plataformas para comprender la historia en su totalidad.

6. Realidad aumentada: superpone objetos o animaciones generadas por ordenador sobre la imagen en tiempo real que recoge una cámara web

7. App toy: aplicaciones que "incluyen complementos fisicos, normalmente juguetes, diseñados para interactuar con ellas" (Gómez Díaz et al., 2016) QR, etc.)

8. Libros híbridos: combinan libros en papel con tecnología (códigos

Hemos abandonado, por tanto, el periodo de lectura extensiva que sucedió a la lectura intensiva medieval y nos hallamos, afirma Soccavo (2013), en un periodo hipertextensivo caracterizado por una gran variedad de textos impresos y digitales. La convergencia de elementos como la realidad aumentada o el Internet de la cosas nos está conduciendo hacia una época de metalectura inmersiva: cada lector con su entorno específico "se convierte así potencialmente en una biblioteca" (Soccavo, 2013)

\section{Cogito ergo lego: ¿Qué hace nuestro cerebro cuando leemos?}


Desde un punto de vista biológico, afirma la investigadora Maryanne Wolf (2008), el ser humano no está programado para leer. Aprendimos a leer recientemente y lo hicimos gracias a la plasticidad de nuestro cerebro, que tuvo que readaptar sus circuitos y establecer nuevas conexiones neuronales. Las actuales técnicas de neuroimagen nos confirman esta readaptación. Aplicadas a primeros lectores, permiten visualizar las áreas de actividad en las que se establecen nuevas conexiones: regiones diseñadas para otras funciones (visión, motricidad y lenguaje) aprenden a interactuar.

Nuestro sistema lector, tal y como lo conocemos actualmente, es el resultado de la evolución de nuestro cerebro a lo largo de más de 5000 años, y está formado por cuatro niveles de procesamiento, cada uno de los cuales requiere varios procesos cognitivos que comienzan con un análisis visual del texto y finalizan con la integración del mensaje contenido en ese texto en nuestros conocimientos (Cuetos, 2013):

- Nivel perceptivo y de identificación de letras: el sistema visual analiza el mensaje escrito y por medio de fijaciones y desplazamientos oculares sobre el texto desciframos los signos gráficos que son proyectados sobre nuestro cerebro. Los periodos de fijación nos permiten recoger información y su duración depende del grado de dificultad del texto. La hipótesis más extendida acerca de lo que sucede durante la fijación es que la información se almacena en la memoria icónica y pasa a la memoria operativa, que realiza un análisis categorial del estímulo y lo retiene como material lingǘstico.

Según el modelo de Procesamiento Distribuido en Paralelo (PDP) de McClelland y Rumelhart (1981, citado en Cuetos, 2013) ante una palabra, el sistema trata de identificar los rasgos de las letras mediante nodos (un nodo detecta la líneas verticales, otro las horizontales, un tercero las curvas, etc.). Así mismo, hay un nodo para cada una de las letras de nuestro alfabeto y otro para cada palabra que conocemos. Cuando los nodos de rasgos recogen información, activan los de letras y éstos los de palabras. El trabajo en los distintos niveles no es secuencial sino paralelo.

- Nivel de procesamiento léxico o de reconocimiento visual de las palabras: de cada palabra recuperamos su fonología (cuando leemos en voz alta) y su significado (si hacemos una lectura comprensiva). Hay determinadas características de las palabras que influyen en los tiempos de reconocimiento y lectura. Así, reconocemos más rápidamente y con mayor facilidad las palabras reales que las inventadas (lexicalidad), las de alta frecuencia, las palabras que se aprenden a una edad más temprana, las que tienen un significado fácil de imaginar (imaginabilidad), las palabras con vecinos ortográficos como casa, cosa y las más cortas.

El modelo más consolidado para explicar cómo accedemos al significado de las palabras escritas es el dual: hay una vía léxica que 
permite leer las palabras conocidas (regulares e irregulares) pero no las desconocidas ni las pseudopalabras, y una vía subléxica, que permite leer las palabras regulares (conocidas o no) y las pseudopalabras pero no las irregulares. La velocidad con la que leemos una palabra está condicionada por la calidad y cantidad de nuestro conocimiento semántico (Wolf, 2008). Es decir, cuanto más familiarizados estamos con un término, más rápidamente lo leemos. Diversos estudios (Biemiller, 2012; Snow, 2002) demuestran la incidencia del desarrollo léxico de los niños pre-lectores en el posterior proceso de adquisición de la lectura y en la comprensión lectora.

- Nivel de procesamiento sintáctico: las palabras aisladas no aportan información nueva ya que el mensaje se encuentra en la agrupación de las palabras en unidades mayores y en la relación entre ellas. No obstante, este nivel no analiza el significado de las oraciones sino la relación entre los constituyentes de las mismas. Para ello, el lector dispone de unas claves presentes en la oración: orden de las palabras, su significado, palabras funcionales (conjunciones, preposiciones, etc.) y signos de puntuación. Mientras leemos, hacemos uso de ese conocimiento para determinar la estructura de las oraciones.

- Nivel de procesamiento semántico: los lectores extraemos el mensaje y construimos una representación mental del texto integrándola en nuestros propios conocimientos. En ella aparecen las ideas principales que recogen el sentido general (no literal), así como la información no explícita que el lector aporta a partir de sus propios conocimientos. Esta representación es, en palabras de Cuetos (2013) "el punto de encuentro entre el lector y el texto, entre el mensaje expresado en el texto y los conocimientos aportados por el lector". Se produce así la fusión entre el mundo del texto y el del lector: el lector interpreta el sentido del texto y se apropia de él (Ricoeur, 2004)

Según Kintsch y Van Dijk (1978), autores de una de las teorías más conocidas sobre la formación de las estructuras mentales a partir de textos, hay tres niveles de representación: texto de superficie, en el que construimos una primera representación literal mientras leemos las palabras y las mantenemos en la memoria operativa durante un breve lapso para extraer las proposiciones que componen la oración; texto base, en el que, a partir del texto de superficie, construimos proposiciones que recogen las ideas principales y que recordamos durante un tiempo relativamente prolongado; modelo de situación, en el que construimos una macroestructura con la que formamos una representación más abstracta que dura un tiempo indefinido y que combina la información del texto con la que nosotros mismos poseemos. Según GarcíaMadruga (2006), para comprender un texto el lector necesita cinco tipos de conocimiento: lingüísticos (sobre el contenido del texto que está leyendo), generales sobre el mundo, referentes a la estructura de los textos (el lector se 
crea expectativas diferentes sobre el tipo de estructura que tiene que construir en función de si está ante una novela, un artículo científico, etc.), estratégicos y metacognitivos (el lector tiene que saber cuál es el propósito de la lectura para determinar qué estrategias necesita, ser capaz de comprobar si ha comprendido el texto, localizar problemas y buscar soluciones).

Las técnicas de neuroimagen muestran la activación de determinadas áreas del cerebro cuando leemos. Esta actividad se incrementa a medida que el lector adquiere mayor destreza, especialmente en el área de Broca de los hemisferios derecho e izquierdo y en varias áreas temporales y parietales (Wolf, 2008).

Siendo éstos los procesos que tienen lugar mientras leemos en "analógico", cabe preguntarnos qué sucede en nuestro cerebro cuando leemos en "digital" y en qué medida influyen las características físicas de los dispositivos, el enriquecimiento de los textos mediante hiperenlaces y elementos audiovisuales o la conexión simultánea del lector a las redes sociales.

A este respecto, existen numerosos estudios científicos que comparan la lectura en ordenador y la lectura en papel. La mayoría pone de manifiesto las diferencias a favor de esta última en las puntuaciones obtenidas por los sujetos de estudio. Las investigaciones se han vertebrado, fundamentalmente, en torno a los siguientes elementos:

- Velocidad lectora: la velocidad media de lectura se sitúa entre 150 y 400 palabras por minuto. Esta variabilidad está en función de la persona y del tipo de texto, de modo que para una lectura recreativa (de una novela, de un periódico, etc.) se desarrolla una velocidad mayor que para una lectura profunda (destinada a la asimilación de los contenidos). Estudios como el de Daniel y Woody (2013) o Kerr y Symons (2006) demuestran que la velocidad lectora también se ve afectada por el soporte y que el tiempo requerido para la lectura de un texto impreso es menor.

- Comprensión: en varias investigaciones los sujetos obtienen puntuaciones más altas en comprensión lectora cuando leen en papel. Kerr y Symons (2006) relacionan la comprensión y la velocidad lectora y concluyen que cuando los sujetos disponen de un tiempo no limitado, son capaces de comprender los textos en la misma medida en cualquiera de los dos soportes. Si, por el contrario, el tiempo de que disponen para leer se limita, las puntuaciones son más bajas cuando el sujeto lee en ordenador. Mangen, Walgermo y Bronnick (2013) realizaron su investigación con textos lineales (carentes de hipertexto) tanto narrativos como expositivos. Los sujetos que leyeron en papel obtuvieron puntuaciones significativamente más altas que los que lo hicieron en ordenador, cualquiera que fuera el contenido, y atribuyen 
esta diferencia a la dificultad para construir un mapa mental de la totalidad del texto digital.

- Metacomprensión: investigaciones como la de Ackerman y Goldsmith (2011) demuestran que las puntuaciones obtenidas en los tests aplicados en un entorno de estudio con tiempos controlados no varían entre la pantalla y el papel. Si los tiempos son autorregulados por los propios estudiantes, la puntuación es más baja en pantalla. Las diferencias, concluyen, no son tanto cognitivas como metacognitivas, es decir, los sujetos de estudio tienen la autopercepción de que no absorben los contenidos de igual modo.

- Funciones ejecutivas: las funciones ejecutivas controlan los procesos cognitivos y determinan cómo, cuándo y en qué orden llevamos a cabo las tareas. Son muy importantes para la realización de la mayor parte de las actividades diarias que llevamos a cabo: toma de decisiones, resolución de problemas, multitarea, etc. Numerosos estudios ponen de manifiesto los problemas asociados a la multitarea, entre los que figura la disminución de la atención, un menor rendimiento y una elevación del nivel de estrés. De este modo, el enriquecimiento de un texto con hipervínculos, sonido, acceso a redes sociales, etc., puede afectar a la capacidad de atención del lector. Las investigaciones relativas a los efectos de la multitarea en la lectura concluyen que la estructura hipertextual tiende a incrementar la demanda cognitiva en la toma de decisiones y en el procesamiento visual y que esta sobrecarga cognitiva perjudica la comprensión lectora (DeStefano y LeFevre, 2007). Otros estudios muestran cómo leer y trabajar con un ordenador conlleva un mayor estrés y esfuerzo cognitivo que hacer ambas tareas simultáneamente en papel (Wästlund, 2005).

- Memoria: Noyes y Garland (2003) se han centrado en el modo en que los textos impresos y digitales son procesados cognitivamente, asimilados y recuperados. Para valorar la naturaleza y calidad de lo que recordamos, estos investigadores se basaron en el paradigma saberrecordar deTulving (1985), según el cual los sujetos pueden distinguir entre respuestas procedentes de un recuerdo y respuestas procedentes de un conocimiento, y que influyen variables como el intervalo de retención y el nivel de procesamiento. El conocimiento que se recuerda se asocia a un contexto concreto y a la memoria operativa y se olvida o se difumina con el tiempo, en tanto que el conocimiento que se sabe se vincula a un conocimiento del mundo y a la memoria semántica (independiente de contextos concretos como el de aprendizaje) y se mantiene a largo plazo. Noyes y Garland encontraron diferencias entre los sujetos que leyeron en ordenador y los que lo hicieron en papel, de modo que en el primer grupo la frecuencia de lo recordado fue el doble de lo sabido, en tanto que en el segundo, los niveles de lo recordado y lo sabido fueron similares. Los investigadores concluyen que las características de la 
pantalla (luminosidad, contraste, velocidad de refresco, etc.) interfieren en los procesos cognitivos de la memoria a largo plazo. El conocimiento se asimila y se recupera mejor cuando se presenta impreso.

- Estrategias de lectura: los estudios de eyetracking de Jakob Nielsen (2006) muestran que cuando leemos contenidos en la web la mirada dibuja un patrón dominante de lectura en forma de F (primero, hacemos una lectura horizontal en la parte superior de la pantalla; a continuación, descendemos ligeramente y realizamos un movimiento horizontal que cubre un área más pequeña que la anterior; finalmente, hacemos un movimiento vertical que escanea la parte izquierda del texto). No leemos, por tanto, linealmente palabra por palabra sino que escaneamos el texto. A partir de este descubrimiento, Nielsen propone unas pautas para publicar en Internet y recomienda no escribir más del $50 \%$ de lo que escribiríamos en una versión en papel, hacerlo en bloques cortos y facilitar la localización de información por medio de encabezamientos significativos y subrayados o negritas que ayuden a encontrar las palabras clave.

$\mathrm{Si}$ extrapolamos estas investigaciones a la lectura de libros digitales cabe preguntarnos si empleamos estas mismas estrategias y en qué medida soporte y contenido condicionan las mismas. La respuesta es afirmativa para Wolf (2007, 2008) y Baron (2015): la lectura digital estaría modificando nuestra forma de leer, de modo que la lectura en profundidad y lineal está siendo sustituida por una lectura superficial con la que se capta una idea general pero no los detalles (skimming) o simplemente se explora el texto en busca de una información específica (scanning). Esta "hiper-lectura", es consecuencia de la hiper-atención" (Hayles, 2007) caracterizada por constantes cambios en el foco de atención de las tareas, preferencia por múltiples canales de información, necesidad de un alto nivel de estimulación y baja tolerancia al aburrimiento.

En este contexto, Wolf (2007) afirma que un tipo diferente de lectura está creando un tipo distinto de pensamiento y propugna la necesidad de que los niños desarrollen un cerebro lector "experto" antes de sumergirse en el mundo digital.

Por su parte, Baron (2015) observa que también la forma de escribir está cambiando, de modo que muchos autores y editores publican obras más breves o que no requieren una lectura profunda ni reflexiva.

El conjunto de estas investigaciones refleja los cambios, resistencias y adaptaciones que los nuevos soportes de lectura están provocando. Por el contrario, otros estudios (Lei et al., 2010; Johnson 2013) muestran que no hay diferencias significativas entre leer en papel y en digital. Según la investigación 
de Johnson, tampoco influye el grado de experiencia previa del sujeto en el manejo de los dispositivos. La encuesta y los grupos de discusión creados por Johnson aportan información de interés: el 88,8\% de los estudiantes afirma leer libros en portátiles, netbooks y ordenadores de sobremesa, un 51,1\% usa iPads, iPhones o iPods, el 36,1 \% en móviles, el 33,5\% en lectores de libros electrónicos, el 1,7\% en tabletas Android y el 3,9\% en ninguno. La mayoría de los participantes se decanta por los dispositivos con precios más bajos y expresan su preocupación por el esfuerzo visual que acarrea la lectura en ellos y la distracción que supone Internet, el correo electrónico, las redes sociales y los juegos. Así mismo, muestran su disconformidad con los altos precios de los libros electrónicos y la imposibilidad de su reventa.

\section{E1 público lector en el momento actual: ¿analógicos vs digitales?}

En 1995 Nicholas Negroponte publica Being digital. Desde entonces, las declaraciones anunciando el fin del libro impreso no han dejado de sucederse. No obstante, el informe anual de 2015 de la Association of American Publishers (2015) muestra una tendencia a la baja en las ventas del libro electrónico y un aumento del libro impreso, que sigue dominando el mercado editorial (libro electrónico, audiolibro y "otros" suponen un 25\% de la cuota de mercado). En España, según el informe Comercio interior del libro en España 2014 de la Federación de Gremios de Editores de España (2016) las cifras de venta del libro electrónico lo sitúan al alza, si bien su cuota de mercado es tan sólo del 3\%, tal y como recoge el Informe anual del libro digital2015 (Libranda, 2016). Hay claros indicios, por tanto, de que la lectura "analógica" y la digital van a convivir más tiempo del esperado y que esta dualidad está dando lugar a la aparición de un público lector heterogéneo que lee en uno u otro formato, en ambos, que alterna pantallas o se decanta por un solo dispositivo.

La tradicional división lector analógico / lector digital deja de tener sentido en un contexto en el que una parte de la población lee en ambos formatos y lo hace en las formas más variadas: correos electrónicos, prensa, mensajes en las redes sociales, artículos, libros. Leemos más extensivamente que nunca y lo hacemos menos intensivamente que en cualquier otra época.

Particularmente útil a nuestros objetivos es la clasificación de los lectores planteada por Revelle et al. (2012) en función de la relación de éstos con los distintos soportes, la tecnología y su experiencia lectora: los amantes del libro aprecian los libros como objetos físicos, asocian el placer de la lectura únicamente al libro impreso, no les gusta leer textos largos en pantalla y creen que no son capaces de absorber la información cuando leen en digital; los tecnófilos están muy interesados en la aplicación de las nuevas tecnologías al libro, consideran que las ventajas del libro electrónico, en lo que a búsqueda y acceso respecta, sobrepasan con creces cualquier desventaja, les estimula ser 
capaces de buscar sin necesidad de acudir a una biblioteca y no tienen inconveniente en leer en pantalla; los pragmáticos están más interesados en el contenido que en el soporte y son capaces de apreciar los pros y contras del formato digital y del papel, les interesa la posibilidad de búsqueda que ofrece el libro electrónico porque les permite filtrar los contenidos (si bien consideran que su propia falta de habilidad para hacer anotaciones en el texto electrónico interrumpe su flujo de trabajo) y prefieren no leer un libro completo en pantalla; los impresores eligen el libro impreso pero, a diferencia de los amantes del libro, tienen dificultades en el manejo de libros electrónicos, no pueden leer en pantalla y tienen la necesidad de imprimir los textos digitales con los que trabajan.

La investigación de Revelle et al. nos lleva a preguntarnos hasta qué punto los mecanismos y procesos cognitivos que se ponen en marcha cuando leemos determinan que un lector tenga una mayor predisposición hacia lo digital o hacia lo impreso. Existen factores exógenos que hacen que la experiencia lectora en digital sea percibida como negativa o no lo suficientemente positiva:

- El sistema de gestión de derechos mediante Digital Rights Management (DRM) penaliza al lector: requiere ciertos conocimientos técnicos, asocia el libro digital al dispositivo en lugar de al usuario, etc. Si bien el DRM blando o social (a través de la marca de agua o de la huella digital) supone una alternativa (Eguaras, 2015), su uso todavía es residual.

- El concepto de propiedad no está claro para muchos lectores, que pueden donar o prestar un libro impreso pero no pueden hacer lo mismo cuando éste es digital.

- Existen ciertas resistencias y desconfianzas entre una parte del sector editorial, que lanza las novedades en papel y pospone su salida en digital.

- Los lectores más concienciados con el medio ambiente aducen que los materiales de los que están hechos los dispositivos, a diferencia del libro impreso, no son reciclables y que los libros digitales requieren de grandes granjas de servidores para su almacenamiento, con el consiguiente consumo de electricidad para su mantenimiento y refrigeración.

No obstante, son los factores endógenos y psicológicos asociados a la lectura en sí misma los que parecen tener una mayor relevancia a la hora de que un lector se decante por un soporte u otro:

- En 2001, Marc Prensky acuñó el término nativo digital para designar a los hablantes nativos del lenguaje digital de juegos de ordenador, vídeo e Internet. En contraposición, los inmigrantes digitales son aquéllos que viven en un mundo digital y han tenido que aprender ese lenguaje. Tanto la neurobiología como la psicología social, afirma Prensky, 
aportan pruebas de que los patrones de pensamiento cambian en función de las experiencias del individuo.

Otra diferencia fundamental entre nativos e inmigrantes es la relativa al sentimiento de identidad con las tecnologías. Para los inmigrantes el móvil, Internet o las redes sociales son herramientas para interactuar con el mundo real, en tanto que los nativos sienten las tecnologías como una extensión de sí mismos (Olmo, 2008).

De todo ello podemos colegir que el cerebro del nativo digital, acostumbrado a la multitarea, la hipertextualidad y la hiperconectividad, necesariamente afrontará la lectura digital desde estrategias cognitivas distintas a las empleadas por los inmigrantes. Del mismo modo, la actitud y expectativas también serán diferentes en uno y otro caso.

- Las pantallas retroalimentadas de tabletas, móviles y ordenadores producen fatiga visual, por lo que hay lectores que prefieren el libro impreso cuando se trata de una lectura prolongada. Las sensaciones habitualmente referidas son: visión borrosa, lagrimeo, fotofobia, visión doble, sequedad, dolor de cabeza e incluso náuseas. La tinta electrónica de los dispositivos dedicados (lectores de libros electrónicos) evita estos efectos y proporciona una experiencia más similar a la de la lectura en papel, si bien no ofrece la posibilidad de imágenes en color ni en movimiento. Las investigaciones en este campo permiten vislumbrar una mejora sustancial gracias a la tecnología electrowetting (quesepara la reproducción del contenido en capas, grises por un lado y color por otro) y a la electoluminiscencia orgánica (más conocida como OLED, consistente en capas orgánicas semiconductoras situadas entre dos electrodos). Pero, sin duda, es el grafeno el que ha levantado mayor expectación, un material con una gran conductividad, resistencia y flexibilidad que permitirá fabricar pantallas enrollables y plegables a bajo coste.

Cualquiera que sea la tecnología que acabe imperando, las pantallas tendrán una mayor resolución y precisión, proporcionarán una visualización más fluida de imágenes en color y en movimiento y harán que la lectura sea más cómoda en cualquier dispositivo.

- Para algunos lectores, la duración de las baterías de los dispositivos móviles supone una clara desventaja frente al libro impreso ya que la lectura puede verse interrumpida. No obstante, las pantallas de tinta electrónica de los ereaders sólo consumen energía cuando el usuario pasa de página, por lo que la duración de la batería es muy superior. La aplicación generalizada de la tecnología electrowetting, la electroluminiscencia orgánica y el grafeno aportarán un ahorro considerable en el consumo de energía y, por tanto, una mayor duración de las baterías.

- Tabletas, móviles y ordenadores permiten reproducir contenidos sonoros y audiovisuales de audiolibros, videolibros, libros enriquecidos, transmedia y crossmedia. Esta posibilidad, percibida por algunos lectores como una ventaja que sitúa a estos dispositivos por encima de los 
ereaders y del libro impreso, supone para otros una distracción que impide una lectura comprensiva y profunda del texto.

- La posibilidad de navegar, de comunicarse a través de redes sociales (generalistas o de lectura) y, en definitiva, de estar permanentemente conectados, hace que algunos lectores se decanten por las tabletas, móviles y ordenadores. El ereader ofrece una experiencia de navegación limitada (la conexión es más lenta y las imágenes no se visualizan en color), si bien esta limitación de los ereaders y de los libros impresos es percibida por otros lectores como una forma de evitar las distracciones e interrupciones que conlleva la multitarea (disminución de la capacidad de atención, elevación del nivel de estrés, etc).

- Hemos visto cómo cuando un lector se enfrenta a un texto requiere un conocimiento estratégico y metacognitivo: necesita saber qué propósito tiene la lectura para determinar qué estrategias va a utilizar o si ha comprendido el texto. Este tipo de conocimiento incide, necesariamente, en la estrategia de elección de uno u otro soporte de lectura en función de la finalidad de la misma y su extensión. De este modo, el teléfono móvil se adecua a una lectura rápida, un ereader a una lectura recreativa y comprensiva, en tanto que un ordenador sirve de manera más efectiva a los propósitos de lectura en relación con la realización de trabajos académicos. Estudios como el de Baron (2015), sin embargo, muestran cómo los lectores prefieren el libro impreso por encima de cualquier dispositivo cuando se trata de textos recreativos o de estudio (en mayor medida cuanto más extensos son).

En lo que respecta a los aspectos metacogitivos, éstos pueden verse influidos por unas bajas expectativas del lector, por su destreza en relación con las nuevas tecnologías, etc.

- La variedad de dispositivos (tabletas, ereaders, ordenadores, teléfonos móviles), sistemas operativos (iOS, Android, Windows) y programas (DRM, apps, etc.), la obsolescencia del hardware y software, la posibilidad de lectura en streaming o mediante descarga y la diversidad de plataformas de adquisición y préstamo de libros electrónicos inciden en la curva de aprendizaje y en la experiencia lectora provocando en algunas personas estrés tecnológico.

- Para ciertos lectores la experiencia sensorial (táctil, visual y hasta olfativa) que proporciona el libro impreso es un atractivo que no puede ofrecer el libro digital. Así, el primero permite "ojear y hojear el texto con más comodidad e inmediatez". y "ponderar de un vistazo lo que llevamos leído y lo que nos falta por leer. Es cierto que esta información numérica se halla también en la parte inferior o superior de la página electrónica, pero su ponderación es menos sensorial e inmediata." (Gubern, 2010). La corporeidad del libro impreso da al lector un sentido de la totalidad del texto frente a la fragmentación del libro digital. 


\section{Conclusiones}

La visión contextualizada en el tiempo a través de una perspectiva transhistórica y cultural nos muestra cómo la lectura en el presente es un trasunto de su propia historia. La rápida circulación de ideas y de textos, la lectura como acto social, su democratización o los nuevos soportes no son acontecimientos tan recientes como pudiéramos pensar. La tensión impreso/digital es una más de las dicotomías que se han producido a lo largo de la historia (oralidad/escritura, libro manuscrito/impreso, etc.) impregnadas, todas ellas, de la visión apocalíptica de detractores e integrada de defensores y finalmente resueltas positivamente.

Desde un punto de vista cognitivo, la mayor parte de los estudios se centran en la lectura en ordenador. Es necesario contar con un mayor número de investigaciones que evalúen la comprensión lectora, velocidad, retención, etc. de los sujetos de estudio cuando leen en dispositivos móviles (tablets, lectores de libro electrónico y móviles), estableciendo una comparativa entre los resultados obtenidos con cada tipo de dispositivo y entre éstos y el libro impreso. Del mismo modo, también son necesarias investigaciones basadas en técnicas de neuroimagen que corroboren qué áreas de nuestro cerebro se activan cuando leemos en digital frente a las regiones que registran mayor actividad cuando nuestro cerebro lee en analógico. Sólo a través de estas investigaciones podremos determinar hasta qué punto la lectura digital está cambiando nuestra forma de leer.

En cualquier caso, es probable que ambos soportes (impreso y electrónico) convivan más tiempo de lo que auguraban los pronósticos iniciales. Razones culturales, generacionales e incluso neurológicas, nos llevan a concluir que la lectura en papel está llamada a perdurar, si bien un nuevo tipo de público lector, capaz de alternar soportes, se abre paso en el ecosistema del libro. Preservar lo bueno de ambos sistemas debe ser uno de los cometidos de las generaciones actuales para las venideras.

\section{Bibliografía}

ACKERMAN, R. y GOLDSMITH, M., 2011. Metacognitive Regulation of Text Learning: On Screen versus on Paper. Journal of Experimental Psychology: Applied, 17 (1), 18-32.

ASSOCIATION OF AMERICAN PUBLISHERS, 2016. StatShot Annual Survey [en línea]. Washington D.C.: APA [Consulta: 30 abril 2017]. Disponible en: http://newsroom.publishers.org/us-publishing-industrys-annual-surveyreveals-nearly-28-billion-in-revenue-in-2015

BARON, N.S., 2015. Words Onscreen: The Fate of Reading in a Digital World. New York: Oxford University Press. ISBN 978-0-19-931576-5

BIEMILLER, A., 2012. The Influence of Vocabulary on Reading Acquisition. En: 
Encyclopedia of Language and Literacy Development. [en línea]. London (Ontario): Western University. [Consulta: 30 abril 2017]. Disponible en: http:/ / citeseerx.ist.psu.edu/viewdoc/download?doi=10.1.1.627.9513\&rep $=\mathrm{r}$ ep1\&type $=$ pdf

CAVALLO, G., 2001. Entre el volumen y el codex. La lectura en el mundo romano. En: G. CAVALLO y R. CHARTIER, eds. Historia de la lectura en el mundo occidental. Madrid: Taurus, pp. 109-152. ISBN 84-306-0431-6

CHARTIER R., 2001. Lecturas y lectores populares desde el Renacimiento hasta la época clásica. En: G. CAVALLO y R. CHARTIER, eds. Historia de la lectura en el mundo occidental. Madrid: Taurus, pp. 469-493. ISBN 84-306-0431-6

CUETOS, F., 2013. Psicología de la lectura. $8^{\mathrm{a}}$ ed. Madrid: Wolters Kluwer. ISBN 97884-7197-900-1

DANIEL, D.V. y WOODY, W. D., 2013. E-textbooks at what Cost?. Performance and Use of Electronic vs. Print Texts. En: Computers in Education, 62(marzo 2013), 18-23. doi: 10.1016/j.compedu.2012.10.016

DESTEFANO, D., y LEFEVRE, J.A., 2007. Cognitive Load in Hypertext Reading: A Review. Computers in Human Behavior, 23(3), 1616-1641. ISSN 0747-5632. doi:10.1016/j.chb.2005.08.012

EGUARAS, M. (2015). Seguridad y piratería del libro electrónico: DRM ¿¿í o no? Alternativas. [en línea] En: $V$ Jornadas-Taller de formación sobre libro electrónico 2015. 1-2 Junio. Madrid: UNE; CSIC. [Consulta: 29 abril 2017]. Disponible en:

http:/ /www.une.es/media/Ou1/Image/webmayo2015/Seguridad $\% 20 y \% 20$ pirater $\%$ C3 $\%$ ADa $\% 20$ del $\% 20$ libro $\% 20$ electr $\%$ C3 $\%$ B3nico $\% 20-D R M \% 20$ $\% 20$ Mariana $\% 20$ Eguaras.pdf

FEDERACIÓN DE GREMIOS DE EDITORES DE ESPAÑA, 2015. Comercio interior del libro en España 2014 [en línea]. Madrid: Federación de Gremios de Editores de España [Consulta: 27 abril 2017]. Disponible en: http://federacioneditores.org/img/documentos/Comercio_Interior_14.pdf

GARCÍA-MADRUGA, J.A., 2006. Lectura y conocimiento. Barcelona: Paidós. ISBN 978-84-493-1895-5

GÓMEZ-DÍAZ, R., GARCÍA RODRÍGUEZ, A, CORDÓN GARCÍA, J.A. y ALONSO ARÉVALO, J., 2016. Leyendo entre pantallas. Gijón: Trea. ISBN 97884-9704-945-0

GUBERN, R., 2010. Metamorfosis de la lectura. Barcelona: Anagrama. ISBN 978-84339-6309-3

HAYLES, N.K., 2007. Hyper and Deep Attention: The Generational Divide in Cognitive Modes. Profession, 13, 187-199. ISSN 0740-6959

JOHNSON, J.W., 2013. A Comparison Study of the Use of Paper versus Digital Textbooks by Undergraduate Students [en línea].Terre Haute: Indianan State University [Consulta: 26 abril 2017]. Disponible en:http://hdl.handle.net/10484/5376

KERR, M. A. y SYMONS, S. E., 2006. Computerized presentation of text: Effects on Children's Reading of Informational Material. Reading and Writing, 19(1), 1-19. ISSN 0922-4777

KINTSCH, W. y VAN DIJK, T., 1978. Towards a Model of Discourse Comprehension and Production. Psychological Review85(5), 363-394. ISSN 0033-295X 
KNOX, B., 1968. Silent Reading in Antiquity. Greek, Roman and Byzantine Studies, IX, 421-425 (citado por SVENBRO, J., 2001. La Grecia arcaica y clásica. La invención de la escritura silenciosa. En: G. CAVALLO y R. CHARTIER, eds. Historia de la lectura en el mundo occidental. Madrid: Taurus, pp. 67-108. ISBN 84-306-0431-6)

LEI, S., RHINEHART, P.J., HOWARD, H.A. y CHO, J.K., 2010. Strategies for improving readingcomprehension among college students. Reading Improvement, 47(1), 30-42. ISSN 0034-0510

LIBRANDA, 2016. Informe anual del libro digital 2015 [en línea]. Barcelona: Libranda [Consulta: 27 abril 2017]. Disponible en: http:/ / libranda.com/informe-anual-del-libro-digital-2015/

LYONS, M., 2001. Los nuevos lectores del siglo XIX: mujeres, niños, obreros. En: G. CAVALLO y R. CHARTIER, eds. Historia de la lectura en el mundo occidental. Madrid: Taurus, pp. 539-589. ISBN 84-306-0431-6

MANGEN, A., WALGERMO, B. R., BRONNINCK, K., 2013. Reading linear Texts on Paper versus Computer Screen: Effects on Reading Comprehension. International Journal of Educational Research. 58, 61-68. ISSN 0883-0355

MANGUEL, A., 2012. Una historia de la lectura. Madrid: Alianza. ISBN 978-84-2060890-7

McCLELLAND, J.L. y RUMELHART, D.E., 1981. An Interactive Activation Model of ContextEffects in Letter Perception: Part 1. An Account of Basic Findings. Psychological Review, 88(5),375-407. ISSN 0033-295X (citado por CUETOS, F., 2013. Psicología de la lectura. $8^{a}$ ed. Madrid:Wolters Kluwer. ISBN 978-84-7197-900-1)

McKENZIE, D.F., 1999. Bibliography and Sociology of Texts. NY: Cambridge University Press

NIELSEN, J., 2006. F-Shaped Pattern For Reading Web Content [en línea]. California: Nielsen Norman Group. [Consulta: 27 abril 2017]. Disponible en:https://www.nngroup.com/articles/f-shaped-pattern-reading-webcontent/

NOYES, J. M. y GARLAND, K. J., 2003. VDT versus Paper-based Text: Reply to Mayes, Sims and Koonce. International Journal of Industrial Ergonomics, 31, 411423. ISSN 0169-8141

OLMO, M. J., 2008. Nativo digital, lector multitarea. Notas sobre sobre jóvenes, universidad y lectura en EE UU [en línea]. Educación y biblioteca, Año 20, n. 165, 130-140. [Consulta: 28abril 2017]. Disponible en:https://gredos.usal.es/jspui/bitstream/10366/119529/1/EB20_N165_P 130-140.pdfISSN 0214-7491

POE, M. T., 2010. A History of Communications. Cambridge: Cambridge University Press. ISBN 978-1-107-00435-1

PRENSKY, M., 2001. Digital Natives, Digital Immigrants. On the Horizon, 9(5), 1 6.ISSN 1074-8121

REVELLE, A., MESSNER, K., SHRIMPLIN, A., y HURST, S., 2012. Book Lovers, Technophiles, Pragmatists, and Printers: The Social and Demographic Structure of User Attitudes toward e-Books[en línea]. College \& Research 
Libraries, 73(5), 420-429. [Consulta: 28 abril 20177. Disponibleen:http://crl.acrl.org/index.php/crl/article/view/16251/17697ISS N 2150-6701.doi:10.5860/ crl-288

RICOEUR, P., 2004. Tiempo y narración: configuración del tiempo en el relato histórico. $5^{\mathrm{a}}$ ed. en español. México: Siglo XXI Editores. ISBN 968-23-1965-X (o.c.)

SARTORI, G., 2002. Homo videns: la sociedad teledirigida. Madrid: Taurus. ISBN 978 84-306-0469-2

SNOW, C. E., 2002. Reading for Understanding: Toward a Research and Development Program inReading Comprehension [en linea]. Santa Monica: RAND Education. ISBN 0-8330-3105-8 [Consulta: 28 abril 2017]. Disponible en: http://www.rand.org/content/dam/rand/pubs/monograph_reports/2005/ MR1465.pdf

SOCCAVO, L., 2013. Inventar juntos las nuevas mediaciones del libro. Lectyo.

SVENBRO, J., 2001. La Grecia arcaica y clásica. La invención de la escritura silenciosa. En: G. CAVALLO y R. CHARTIER, eds. Historia de la lectura en el mundo occidental. Madrid: Taurus, pp. 67-108. ISBN 84-306-0431-6

TULVING, E., 1985. Memory and consciousness. Canadian Psychology, 26(1), 1-12. ISSN 0708-5591

WÄSTLUND, E., REINIKKA, H., NORLANDER, T. y ARCHER, T., 2005. Effects of VDT and Paper Presentation on Consumption and Production of Information: Psychological and Physiological Factors. Computers in Human Behavior, 21(2), 377-394. ISSN 0747-5632. doi: 10.1016/j.chb.2004.02.007

WEST, M. y CHEW, H.E., 2015. La lectura en la era móvil: un estudio sobre la lectura móvil enlos países en desarrollo [en línea]. México: UNESCO. [Consulta: 28 abril 2017$].$ Disponible en:http:/ / unesdoc.unesco.org/images/0023/002338/233828s.pdf

WOLF, M., 2007. Socrates' Nightmare [en línea]. The New York Times. New York: The New York Times Company. [Consulta: 28 abril 2017]. Disponible en: http://www.nytimes.com/2007/09/06/opinion/06ihtedwolf.4.7405396.html

WOLF, M., 2008. Cómo aprendemos a leer: historia de la ciencia del cerebro y la lectura. Barcelona: Ediciones B. ISBN 978-84-666-3835-7

\section{Notas}

1. Poe diferencia cinco períodos en la evolución de las comunicaciones humanas: homo loquens, la edad del discurso (18000 a.C. a 3500 a.C.); homo scriptor, la edad de los manuscritos (3500 a.C. a 1450); homo lector, la edad de la imprenta (1450 - S. $\mathrm{XX}$ ); homo videns, la edad de los medios audiovisuales (S. XX); homo somnians, la edad de Internet (desde 2000) 